Correspondence: I. Frachon, Dept of Internal Medicine and Chest Diseases, Hôpital de la Cavale Blanche, F-29609 Brest Cedex, France. E-mail: irene.frachon@chu-brest.fr

Statement of Interest: None declared.

\section{ACKNOWLEDGEMENTS}

The authors wish to thank P. Perfezou (Centre Hospitalier de Cornouailles, Quimper, France) and O. Sitbon (Hôpital Antoine Béclère, Clamart, France) for kindly providing useful medical expertise.

\section{REFERENCES}

1 Sitbon O, Lascoux-Combe C, Delfraissy JF, et al. Prevalence of HIV-related pulmonary arterial hypertension in the current antiretroviral therapy era. Am J Respir Crit Care Med 2008; 177: 108-113.

2 Sitbon O, Gressin V, Speich R, et al. Bosentan for the treatment of human immunodeficiency virus-associated pulmonary arterial hypertension. Am J Respir Crit Care Med 2004; 170: 1212-1217.

3 Zuber JP, Calmy A, Evison JM, et al. Pulmonary arterial hypertension related to HIV infection: improved hemodynamics and survival associated with antiretroviral therapy. Clin Infect Dis 2004; 38: 1178-1185.
4 Sitbon O. HIV-related pulmonary hypertension: clinical presentation and management. AIDS 2008; 22: Suppl. 3, S55-S62.

5 Feiterna-Sperling C, Huseman D, Timme J, et al. Resolution of human immunodeficiency virus type 1 infection-related severe pulmonary hypertension in a very low-birth-weight infant. Pediatr Infect Dis J 2008; 27: 564-567.

6 Speich R, Jenni R, Opravil M, et al. Regression of HIV-associated pulmonary arterial hypertension and long-term survival during antiretroviral therapy. Swiss Med Wkly 2001; 131: 663-665.

7 Pellicelli AM, Barbaro G, Palmieri F, et al. Primary pulmonary hypertension in HIV patients: a systematic review. Angiology 2001; 52: 31-41.

8 Pellicelli AM, D'Ambrosio C, Vizza CD, et al. HIV-related pulmonary hypertension. From pathogenesis to clinical aspects. Acta Cardiol 2004; 59: 323-330.

9 Barbaro G, Lucchini A, Pellicelli AM, et al. Highly active antiretroviral therapy compared with HAART and bosentan in combination in patients with HIV-associated pulmonary hypertension. Heart 2006; 92: 1164-1166.

10 Torre D, Pugliese A. Impact of antiretroviral therapy among HIV-1-infected patients with pulmonary hypertension. Clin Infect Dis 2004; 39: 1549-1550.

\title{
Intravenous $\alpha_{1}$-antitrypsin in a child with deficiency and severe lung disease
}

Hereditary $\alpha_{1}$-antitrypsin deficiency presents with symptomatic obstructive and suppurative lung disease usually in the fourth decade in individuals with a history of smoking [1, 2].

A mature neonate had prolonged icterus due to $\alpha_{1}$-antitrypsin deficiency (PiZZ-type). At 4 weeks of age she developed transient middle lobe atelectasis and persisting hyperinflation on chest radiographs. The patient was hospitalised for virus induced wheezing, bronchopneumonic episodes and atelectasis of the middle lobe many times throughout childhood. Chest computed tomography imaging showed basal emphysema and bronchiectasis in the middle lobe and lingula. Heavy passive smoke exposure was known to have occurred from infancy onward, with active smoking possibly occurring in adolescence for brief periods.

She attended our centre regularly from the age of $12.5 \mathrm{yrs}$. Cystic fibrosis, ciliary dyskinesia, structural bronchopulmonary abnormalities, gastroeso-ophageal reflux-induced lung disease, immune deficiency states, allergies and allergic asthma were excluded. Treatment intensity remained high over the years. At age $14 \mathrm{yrs}$, weekly intravenous augmentation with $60 \mathrm{mg} \cdot \mathrm{kg}^{-1} \cdot$ body weight ${ }^{-1}$ of $\alpha_{1}$-antitrypsin (Prolastin; Bayer, Wuppertal, Germany) was started. Continuous treatment with bronchodilators, inhaled steroids and cefuroxime was left unchanged. Her overall condition improved markedly, and the number of exacerbations, defined according to ANTHONISEN et al. [3], was reduced (fig. 1a) and lung function studies showed decreased airways obstruction and decreased hyperinflation (fig. 1b). Arrest of basal emphysematous changes and bronchiectasis was seen on computed tomography after 4 yrs of treatment. Before $\alpha_{1}$-antitrypsin therapy her bodyweight had been below or at the 3rd percentile for many years and we had encouraged her to take supplemental calories (fig. 1c). Her weight increased rapidly, in association with her improved pulmonary condition, although unintended weight gain subsequently occurred, with dietary intervention being successful only recently.

This is an example of the characteristic course of $\alpha_{1}$-antitrypsin lung disease, which is commonly observed in adults, occurring in a teenager. Among the reasons for such a precocious manifestation of this inherited disease may be as yet unknown endogenous factors and clearly exogenous factors. These included long-standing passive and later possibly active tobacco smoke exposure, frequent and severe lower respiratory tract infections, significant psychosocial family problems and, potentially, malnutrition.

Based on an urgent need for stabilisation of the lung disease and the experience in the adult population, i.v. $\alpha_{1}$-antitrypsinaugmentation therapy was started. According to current 


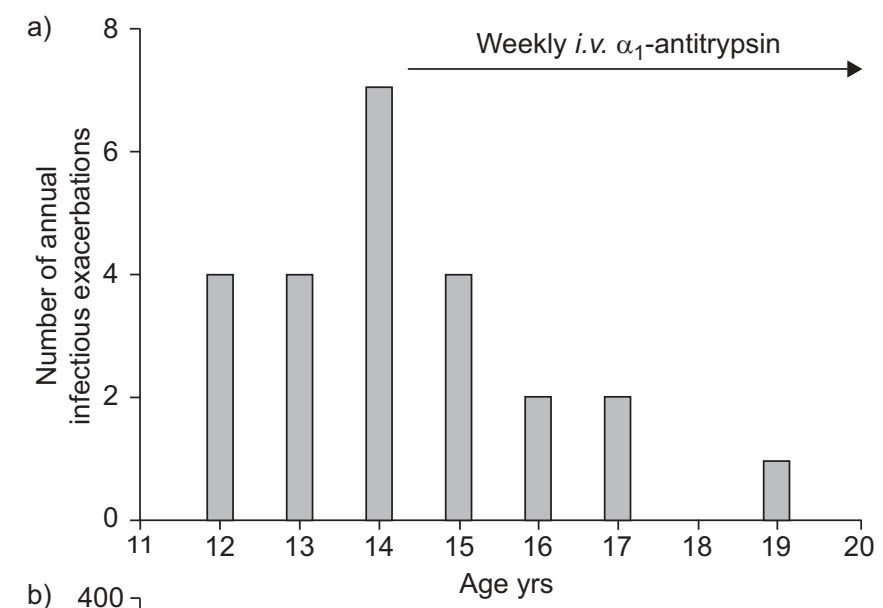

i.v. infusion of $\alpha_{1}$-antitrypsin led to long-term stabilisation, which had not been achieved by all other treatment means in the preceding years.

There are no other case reports in children or adolescents with i.v. $\alpha_{1}$-antitrypsin augmentation for $\alpha_{1}$-antitrypsin deficiencydependent pulmonary disease. Two controlled observational studies are available in adult subjects, which found evidence for a slowed rate of FEV1 decline and decreased mortality with $\alpha_{1}$-antitrypsin augmentation $[4,5]$.

Inhibition of airway neutrophil elastase is considered to be central to arresting the destructive process of neutrophilderived protease activity in pulmonary disease due to $\alpha_{1-}$ antitrypsin deficiency. We believe that the treatment might have worked as there was a chronic surplus of neutrophilic elastase activity from infancy onward, together with passive smoke exposure. We felt this patient was a good candidate for this therapy as the other treatment options had failed. Resolving chronic pulmonary inflammation and infection removed a burden from the child and allowed recovery of respiratory status and weight gain on replacement therapy. Future studies on $\alpha_{1}$-antitrypsin deficiency and augmentation therapy should consider including subjects independent of age.

\section{Griese* and H. Brüggen ${ }^{\#}$}

*Dr Von Haunersches, University of Munich, Munich, and \#Outpatient Practice for Pneumology, Deggendorf, Germany.

Correspondence: M. Griese, Dr. von Haunersches Kinderspital, University of Munich, Lindwurmstraße 4, D80337 Munich, Germany. E-mail: Matthias.griese@med.unimuenchen.de

Statement of Interest: A statement of interest for M. Griese can be found at www.erj.ersjournals.com/misc/statements.dtl

\section{REFERENCES}

1 American Thoracic Society/European Respiratory Society Statement: Standards for the diagnosis and management of individuals with $\alpha-1$ antitrypsin deficiency. Am J Respir Crit Care Med 2003; 168: 818-900.

2 Bernspang E, Sveger T, Piitulainen E. Respiratory symptoms and lung function in 30-year-old individuals with $\alpha$-1-antitrypsin deficiency. Respir Med 2007; 101: 1971-1976.

FIGURE 1. a) Number of annual exacerbations requiring medical intervention, b) lung function assessed by forced expiratory volume in $1 \mathrm{~s}(\bullet)$ and residual volume as a percentage of total lung capacity ( $\mathbf{\square})$ in stable condition, and c) weight (expressed as sex specific percentile).

eligibility guidelines, therapy with i.v. $\alpha_{1}$-antitrypsin confers maximum benefit to patients aged $>18$ yrs with moderate airflow obstruction (e.g. forced expiratory volume in $1 \mathrm{~s}$ (FEV1) $35-60 \%$ predicted) [1]. With the exception of age, these criteria were clearly matched by our patient. Treatment with weekly

3 Anthonisen NR, Manfreda J, Warren CPW, et al. Antibiotic-therapy in exacerbations of chronic obstructive pulmonary-disease. Ann Intern Med 1987; 106: 196-204.

4 Wencker M, Banik N, Buhl R, et al. Long-term treatment of $\alpha-1$ antitrypsin deficiency-related pulmonary emphysema with human $\alpha$-1-antitrypsin. Eur Respir J 1998; 11: 428-433.

5 The Alpha-1-Antitrypsin Deficiency Registry Study Group. Survival and FEV1 decline in individuals with severe deficiency of $\alpha-1$ antitrypsin. Am J Respir Crit Care Med 1998; 158: 49-59.

DOI: $10.1183 / 09031936.00029809$ 